First Submitted: 24 January 2021 Accepted: 29 May 2021

DOI: https://doi.org/10.33182/y.v2i1.1564

\title{
Pedagogias emancipatorias en el Abya Yala: Legados y reflexiones urgentes
}

\author{
Jessica Anahí Visotsky Hasrun ${ }^{1}$
}

\section{Resumen}

Este trabajo se propone aportar al campo de la pedagogía latinoamericana desde las reflexiones que nacen de nuestras intervenciones, desde nuestra praxis. Se recupera el legado de dos contextos politicos y referentes de nuestra América se consideran relevantes: por un lado la Revolución cubana, como un bito en el continente americano y el mundo, por el otro la experiencia en Brasily puntualmente de Paulo Freire. Ambas, gestaron una praxis, que fue resultado de la acumulación de experiencias educativas generadas al calor de los procesos emancipatorios en el continente. Se entiende que cada trabajo que recupere las tradiciones, las miradas y saberes respecto del conocimiento pedagógico y la experiencia acumulada desde la praxis educativa en el contexto de proyectos politicos enmancipatorios en nuestra América, es un aporte relevante que resta aún profundizar. Hay un campo de conocimientos, saberes, experiencias respecto de la educación en el continente que seguir rescatando y visibilizando desde el presente, entendiendo que dichos conocimientos y experiencias dieron lugar a una corriente de pensamiento y acción educativa situada en nuestra América, nacida desde la genuinidad de estos territorios, desde ese bumus gestado desde la revolución baitiana, las luchas indigenas, las luchas por las primeras independencias y las de los años '60 y '70, todas ellas luchas incansables de los pueblos en un continente que no ha dejado de resistir al colonialismo por más de 500 años y que ha gestado una corriente pedagógica al calor de estas resistencias. Asi mismo se recuperan los procesos contemporáneos a los que y en los que la corriente de educación popular está recreando y recreándose.

Palabras clave: Emancipación; pedagogía; educación popular; América Latina

\section{Emancipatory Pedagogies in Abya Yala: Legacies and Urgent Reflections}

\begin{abstract}
This work aims to contribute to the field of Latin American pedagogy from the reflections that arise from our interventions, from our praxis. We recover the legacy of two political contexts and references of our America that we consider relevant: on the one hand the Cuban Revolution, which we consider a milestone in our continent and the world, on the other the experience in Brazil and specifically Paulo Freire. Both gestated a praxis, which was the result of the accumulation of educational experiences developed in the heat of the emancipatory processes in the continent. We understand that each work in this line that recovers the traditions, the views and knowledge regarding the pedagogical knowledge and accumulated experience from the educational praxis in the context of enmancipatory political projects in our America, is a relevant contribution that remains to be deepened. There is a field of knowledge, knowledge, experiences regarding education in our continent that continue to rescue and make visible from the present, understanding that said knowledge and experiences gave rise to a current of thought and educational action located in our America, born from the genuine of
\end{abstract}

\footnotetext{
1 Jessica Anahí Visotsky Hasrun, Profesora Adjunta. Directora del Proyecto de Investigación "Pedagogías críticas, interseccionalidades y derechos humanos: una mirada en territorio desde la investigación participante y las metodologías cualitativas", Departamento de Humanidades. Universidad Nacional del Sur, Argentina.

Correo electrónico: jessicavisotsky@yahoo.com.ar.
} 
these territories, from that humus gestated since the Haitian revolution, the indigenous struggles, the struggles for the first independence and those of the 1960s and 1970s, all of them tireless struggles of the peoples on a continent that has not stopped resisting to colonialism for more than 500 years and that has created a pedagogical trend in the heat of these resistances. We also take a look at the contemporary processes in which and in which the current popular education is recreating and recreating itself.

Keywords: Emancipation; Pedagogy; Popular Education; Latin America

\section{¿Desde dónde se escribe, por qué y para qué?}

Se escribe este artículo desde la praxis en la Universidad Pública en educación de adultos y a partir de experiencias que pretenden vincular y dialogar desde la pedagogía con las organizaciones populares, de trabajadores/as, feministas y de pueblos originarios. Desde un contexto histórico y político en que una crisis sanitaria se inscribe en una profunda crisis civilizatoria, que ha dado lugar a enormes estallidos y procesos de lucha contra el sistema capitalista en todo el mundo desde Chile, Ecuador, Colombia o Bolivia hasta Hong Kong, Kurdistán, Francia o Grecia salvando las diferencias entre las mismas y llegando hasta Estados Unidos y las luchas de los afrodescendientes. Al interior de estas luchas hay debate, construcción y pensamiento político, y en muchos casos estos planteamientos socavan el mismo pensamiento e ideas de la modernidad.

Asistimos a tiempos de crítica a la modernidad, a sus instituciones, a sus lógicas, a sus normas y concepciones del hombre y de la naturaleza; asistimos a partir por ejemplo de modelos de "desarrollo" que están haciendo cuestionar los cimientos mismos que sostienen las economías latinoamericanas en el presente. En este momento de crisis profunda es necesario mirar al pasado para retomar proyectos inconclusos, miradas y paradigmas que son una referencia desde donde mirarnos. Desde la pedagogía la propuesta es indagar en el pasado de ese pensamiento político pedagógico de una genuinidad que es poco valorada y insuficientemente reconocida en la academia. Es una corriente lo suficientemente potente y creativa que se recrea y que necesita ir potenciando sus planteamientos al calor de las luchas indígenas actuales en el continente y al calor de las luchas feministas.

\section{La pedagogía y la corriente educación popular en nuestra América-AbyaYala}

Este trabajo se propone aportar a la pedagogía a partir de reflexiones que son parte de la acumulación de experiencias que abonan a una corriente gestada al calor de los procesos emancipatorios en el continente. Se entiende que cada trabajo que recupere las tradiciones, las miradas y saberes respecto del conocimiento pedagógico y experiencia acumulada desde la praxis educativa en el contexto de proyectos políticos enmancipatorios en nuestra América, es un aporte relevante que resta aún profundizar. Es necesario considerar un hito develador y de notable impacto como lo fue la Revolución cubana de 1959, que marcó una ruptura en el continente, contribuyendo a la crisis de hegemonía de los años ' 60 y '70 en el mundo.

Es preciso leer los planteamientos y desarrollos referidos desde el pensamiento descolonial, entendiendo que muchos de ellos fueron el producto - producido por un humus sociológico fundado en el pensamiento de la modernidad occidental y en si guardan resistencias, así como resabios de esa colonialidad del poder, del saber, del ser, de la naturaleza (Walsh; 2007). Así y todo, este pensamiento es una síntesis de esos procesos de resistencia al colonialismo y en sí guarda también pensamiento y acción resultado de las luchas de liberación libradas en el 
continente, por citar las luchas descolonización de las que Fanon fuera parte y quien condensó un pensar de otros maestros y referentes como Aime Cesarie. Esta tradición afrodescendiente abonando a la pedagogía crítica ha sido señalada por Michel Apple para el caso de Estados Unidos, resulta entonces necesario visibilizar el aporte de los movimientos afrodescendientes en toda América

La historia de la Educación Popular está aún en proceso de construcción, entendida como la experiencia gestada desde tiempos previos a la colonia, ligados a procesos de luchas por las independencias donde se dieron reflexiones pedagógicas sobre las que se ha ahondado en otros espacios. En la historia reciente, desde los años '60 en adelante cuando la revolución cubana triunfara en nuestro continente, un cúmulo de experiencias nacieron en ruptura con la tradición precedente dando lugar a ideas y experiencias de una tradición crítica situada en el continente. Estas experiencias en muchos casos se gestarían desde organizaciones que comenzaron a pensar a la educación, pero no aislada, sino en contextos y proyectos políticos revolucionarios. Esa pedagogía con olor a pólvora de la que habla Moacir Gadotti (2013) como la contrapartida a la que se gestara desde el poder hegemónico a partir de la Alianza para el Progreso y sus lineamientos para el "Desarrollo de las Comunidades", haciendo

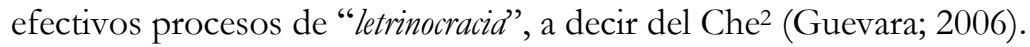

Ha sido señalado (Rodríguez Brandao; 1993; Barquera; 1985) que la Educación Popular, nace en oposición a las formas y técnicas instituidas para el pueblo por los grupos dominantes y al margen de la educación de adultos patrocinada desde la UNESCO. Luego, la misma centralizó las ideas, proyectos y prácticas a través del poder del Estado, lo que le posibilitaría un control mayor sobre las actividades más autónomas y contestatarias.

\section{E1 recorte temporal en los '60 - '70}

Existe una ruptura a partir de los años ' 60 y' 70 , considerando que hay en la pedagogía del continente un antes y un después de la Revolución cubana y puntualmente de la campaña de alfabetización en la isla. En un contexto histórico mundial y latinoamericano de confluencia de procesos que cuestionaron al orden económico, político y social, se produce una radicalización del pensamiento social. En este clima de efervescencia y compromiso se inicia la corriente de pensamiento y acción denominada Educación Popular. El triunfo en 1959 del proceso de la Revolución Cubana, iniciado a principios de esa década, adoptó para Cuba un gobierno socialista que tomó como medida de su gobierno la prioridad de la alfabetización de la población. La Revolución Cubana es un hito en este período que marca el inicio de procesos de lucha por las segundas independencias (Roig; 2003; Pinedo; 2010).

Claudia Gilman sostiene la importancia de considerar el bloque temporal de los sesenta / setenta como época, "con un espesor histórico propio y límites más o menos precisos". Para esta autora,

\footnotetext{
${ }^{2}$ Esta pedagogía hegemónica tiene sus antecedentes teóricos y prácticos en los proyectos de educación no formal de los años '40, con las preocupaciones y esfuerzos vinculados a la situación internacional provocada por la Segunda Guerra Mundial. En dicho contexto de tensiones y luchas por definir espacios económicos y políticos entre los países beligerantes aparece la educación de adultos. Así ante la falta de materias primas para la alimentación en los países de nuestra región, se impulsaron programas para favorecer "el desarrollo" en áreas rurales, financiados generalmente por Estados Unidos. Por otro lado, estaba la concepción de que los aumentos en los índices de alfabetización favorecerían al "desarrollo", se impulsan en estos años las primeras campañas masivas de alfabetización en la región con resultados nada satisfactorios por cierto (Barquera; 1985). Es posteriormente cuando la UNESCO asume el impulso de acciones vinculadas a la concepción de "Educación Fundamental", e impulsa campañas "contra la ignorancia”, que resultaron con resultados también lamentables, aún así se siguieron implementando.
} 
"(...) la distinción entre los sesenta y los setenta carece de sentido si pensamos en que todo el periodo atravesado por una misma problemática: la valorización de la política y la expectativa revolucionaria. Naturalmente, ese proceso de radicalización es móvil, tanto temporal como geográficamente, a lo largo del período, pero la diferencia es de intensidad. Visualizado sobre un mapa en permanente diacronia, se lo observa concentrado aqui, debilitado allá, pero siempre activado en algún lugar del mundo" (2003: 38).

Los orígenes de la marea revolucionaria provenían del Tercer Mundo (el proceso de descolonización africana, la Revolución Cubana, la resistencia vietnamita), o de las clases subalternas del Primer Mundo: la rebelión antirracista en los Estados Unidos y el blackpower, o los diversos brotes de rebeldía estudiantil como el Mayo Francés (Gilman, 2003: 54). Gilman señala que esta época podría entenderse como un período de crisis de hegemonía en el sentido gramsciano, esto es, en los modos habituales del pacto entre dominantes y dominados. Recupera de Gramsci que es una crisis de confianza que afecta a los partidos, se extiende a todos los órganos de la opinión pública, se difunde en toda la sociedad civil, e implica que la clase dirigente deje de cumplir su función económica, política y cultural.

Estos procesos generaron influencias en las mismas instituciones tradicionales, como la iglesia católica, siendo emblemática la reunión del Concilio Vaticano II, encuentro ecuménico reconocido por la Iglesia Católica, convertido en símbolo de la apertura eclesiástica a la edad contemporánea. El mismo fue anunciado por el Papa Juan XXIII el 25 de enero de 1959, y se celebró durante cuatro años consecutivos desde 1962 hasta 1965. La renovación doctrinal y la unión con otras confesiones fueron algunos de los puntos más debatidos. Una de las corrientes religiosas generadas en estos años fue la Teología de la Liberación, un movimiento de interpretación surgido en Latinoamérica que propugna el compromiso que ha de adquirir el cristianismo para erradicar la pobreza y la injusticia social, en cualquier lugar en el que existan pero, de forma muy especial, en el "Tercer Mundo"3. Incluso las iglesias metodistas vieron un cambio en su doctrina, acompañando por ejemplo la lucha de las madres en la Argentina durante el terrorismo de estado iniciado en 1975.

En esta breve genealogía del contexto en que emerge la Educación Popular en América Latina, otro hito fue la Matanza de Tlatelolco, una represión y masacre de estudiantes en la capital deMéxico ${ }^{4}$. En ese mismo año en Europa, los sucesos de mayo de $1968^{5}$, conocidos como el Mayo Francés, inicialmente una manifestación estudiantil en contra del régimen de gobierno pero que generó un cuestionamiento hacia la sociedad capitalista y su lógica.

Toda esta época, los ' 60 y '70, también se caracterizó por una renovación cultural que abarcó todos los ámbitos artísticos (música, arte, cine, literatura, diseño, etc.) y que de diferentes maneras reflejó las nuevas tendencias del pensamiento social. Estos y otros fenómenos sociales, así como pensadores e intelectuales comprometidos, impulsaron el despertar de la

\footnotetext{
${ }^{3}$ Tal como fueran denominados por el economista francés Alfred Sauvi y luego por la CEPAL en Teoría de la Dependencia, los países no centrales, periféricos, no desarrollados, subdesarrollados o en vías de desarrollo.

${ }^{4}$ Los hechos violentos tuvieron lugar en la plaza de Tlatelolco, también llamada de las Tres Culturas, el 2 de octubre de 1968 cuando se realizaba un mitin estudiantil que había congregado a 10.000 personas y formaba parte del movimiento de protesta, iniciado en julio de ese año, contra la actitud gubernamental. Unos 5.000 hombres dotados de equipo blindado y que habían entrado en la plaza con la intención de disolver el acto, repelió a los francotiradores apostados en las azoteas de los edificios contiguos. El fuego, en medio del cual habían quedado atrapados los manifestantes, no cesó hasta las tres de la mañana del día siguiente. Nunca se pudo precisar el número de muertos y heridos. Tampoco se identificó a los responsables de estos hechos sangrientos, pese a lo cual es admitido que se trató, de alguna manera, de un intento de acallar el descontento social por medio de la represión ejercida desde el propio gobierno presidido por Gustavo Díaz Ordaz.

${ }^{5}$ Después de una semana en la que las manifestaciones estudiantiles fueron duramente reprimidas por la policía, los sindicatos obreros convocaron una huelga general apoyada por nueve millones de trabajadores.
} 
conciencia de cambio hacia sociedades más justas y más humanas, creando así el ambiente y el espacio ético e intelectual que dio origen a la Corriente de Educación Popular. La situación de pobreza e injusticia generalizada en América Latina hizo que muchos militantes sociales se sintieran comprometidos con la realidad social. Surgieron grupos, asociaciones comunitarias y expresiones religiosas que buscaban acercarse al pueblo para generar y apoyar las incipientes manifestaciones de organización.

\section{La revolución cubana y la pedagogía revolucionaria}

En el pensamiento de Ernesto Guevara, uno de los referentes de la Revolución puede verse el pensamiento sobre educación. La pedagoga cubana Lidia Turner Martí (2010) ha investigado acerca del pensamiento pedagógico del Che, con una minuciosa lectura entre líneas de diarios, discursos y acciones a lo largo de su vida y hemos indagado también en otros textos en los que Ernesto Guevara tiene intervenciones respecto de la educación (Visotsky; 2012). Remontándonos al año 1952, durante su viaje en motocicleta, el Che conversó con campesinos, obreros, amas de casa, mineros, a quienes les explicó sobre la crueldad del capitalismo, del origen de la explotación del hombre; pues entendía que el mundo sólo podía cambiarse si el hombre comprendía los fenómenos que lo circundaban y así buscaba su libertad y esto lo transmitía en todo momento.

En la sierra maestra, el Che predicaba la unión entre los trabajadores y los campesinos, además desarrolló un trabajo de masas, un trabajo constante educativo con el pueblo, que incluyó la instalación de Radio Rebelde. Baste recordar los infinitos pasajes que nos han llegado de los años en la Sierra Maestra, donde se narra que el Che enseñaba a leer y escribir a los guerrilleros, además se cuenta que el Movimiento 26 de Julio creó escuelas en plena sierra donde se enseñaba a leer y escribir a los campesinos y guerrilleros. La pedagoga cubana Regina Algramonte Rosell en un trabajo de 2014 acerca de la Campaña cubana de Alfabetización afirmaba que,

'Llegada la etapa de la lucha insurreccional en los terrenos de la Sierra Maestra, el Ejército Rebelde dedicó tiempo a la alfabetización de la tropa y en los momentos de descanso estimuló la superación y la lectura en los que ya sabian leer y escribir, asi mismo en los territorios liberados se crearon escuelas para los campesinos de la zona donde daban clase los guerrilleros.

Una vez en el poder el gobierno revolucionario se da a la tarea de cumplir el programa mínimo del Moncada, la tarea fue ardua, se heredaba un sistema político social injusto donde solo la mitad de los niños y niñas de en edad escolar asistía a las escuelas, ubicas en su gran mayoria en lugares de difícil acceso. Solo existían 17000 aulas de las 35000 que se precisaban. Se necesitaba un cambio radical, una revolución cultural que permitiera la implicación consiente de todas y todos los cubanos”. P. 33

El principio político pedagógico del pensamiento de Guevara era "Hacer es la mejor forma de decir", la Pedagogía del ejemplo al decir de Lidia Turner (2010). Se propuso dentro de esta concepción, realizar trabajo voluntario como ejemplo de reeducación del hombre a través del ejemplo revolucionario, del compromiso. Así, después del triunfo de la revolución de 1959, una de las primeras medidas tomadas por el ejército revolucionario fue impulsar una campaña de alfabetización, donde participaron jóvenes egresados de escuelas medias para contribuir con la misma. Esta campaña fue parte de un proyecto político y como relata Algramonte Rosell (2014) se materializó en la movilización y participación popular, para ello se crea la 
40 Pedagogias emancipatorias en el Abya Yala: Legados y reflexiones urgentes

Comisión Nacional de Alfabetización y Educación Fundamental, presidida por el doctor Armando Hart Dávalos, Ministro de Educación.

"Además formaban parte de esta comisión numerosos organismos y organizaciones: las Organizaciones Revolucionarias Integradas (ORI), el Colegio Nacional de Maestros, Central de Trabajadores de cuba (CTC), Asociación Nacional de Agricultores Pequeños (ANAP), Comités de Defensa de la Revolución (CDR), Federación de Mujeres Cubanas (FMC), Asociación de Jóvenes Rebeldes (AJR), Ministerio de las Fuerzas Armadas Revolucionarias (MINFAR), y el Ministerio de Salud Pública (MINSAP)". (Algramonte Rosell; 2014: 33-34).

En el año que duró la campaña de alfabetización se cubrieron las necesidades de alfabetizadores en todas las regiones y zonas del país, de esta forma más de 1000 alfabetizadores, jóvenes entre 14 y 16 años compartieron la vida de los campesinos, pescadores, marineros, carboneros, durmiendo en hamacas, en el suelo, también a la intemperie. (Algrmonte Rosell; 2014:35). Turner relata que las fábricas cubanas detenidas o abandonadas fueron transformadas en espacios de educación (2010). Es relevante donde se inscribe dicha pedagogía y dicha experiencia, y la importancia que entraña el planteamiento del hombre nuevo en el Che para pensar esa pedagogía. La relación entre estructura y subjetividad en sus discursos es de enorme importancia para pensar la educación.

En 1959 Guevara pronuncia un discurso ante intelectuales sobre las proyecciones sociales del ejército rebelde, donde refiere a la cuestión de los principios, partiendo de una anécdota de un guerrillero que antes de la partida del Granma se retira del movimiento y acerca de la falta de principios que el hombre sostenía, el Che afirma: "teníamos que dar ese golpe basados en principios, que lo importante también era saber lo que íbamos a hacer en el poder..." (Ernesto Guevara, citado por Turner; 2010: 91)En 1960 dirigiéndose a los médicos diría en afirmación clara al principio de que se educa aprendiendo y enseñando a la vez, esta mirada que se encuentra más tarde en la obra de Paulo Freire:

"Veremos, entonces, cómo tendremos que ser, en esas circunstancias, un poco pedagogos, a veces un mucho pedagogos; cómo tendremos que ser políticos también; cómo lo primero que tendremos que hacer no es ir y brindar nuestra sabiduría, sino ir a demostrar que vamos a aprender con el pueblo, que vamos a realizar esa grande y bella experiencia común, que es construir una nueva Cuba" (Ernesto Guevara, citado por Turner; 2010:83-84).

Hay una concepción de educación y universidad, él sostenía respecto de la formación en las universidades la necesidad de aprender en contacto directo con los problemas sociales, las prácticas profesionales como centrales, señaló en una oportunidad en un discurso frente a los estudiantes:

“(...) Yo recuerdo que tuve una pequeña conversación con algunos de ustedes hace varios meses, y les recomendaba entrar en contacto con el pueblo, no llegar al pueblo como llega una dama aristocrática a dar una moneda, la moneda del saber o la moneda de una ayuda cualquiera, sino como miembro revolucionario de la gran legión que hoy gobierna a Cuba, a poner el hombro en las cosas prácticas del país, en las cosas que permitan incluso a cada profesional aumentar su caudal de conocimiento y unir, a todas las cosas interesantes que aprendieron en las aulas, las quizás mucho más interesantes que aprenden construyendo en los verdaderos campos de batalla de la gran lucha por la construcción del país” (Ernesto Guevara, citado por Turner; 2010:94-95)

En otra oportunidad, en una mina dirigiéndose a estudiantes de magisterio señalaba: 
"No llegarán como maestros dentro de algunos años solamente a verter a sus alumnos la experiencia lograda en los libros, la historia de los mártires, de los héroes de la Revolución, los que forjaron la nacionalidad aprendida en los libros, ustedes conocerán una parte viva de esta última etapa de la historia. Conocerán los sacrificios, conocerán el contacto con el pueblo conocerán el contacto con las privaciones de los campesinos que todavía hoy subsisten en esta zona, aunque no es ni siquiera un reflejo de lo que ocurría en aquella época..." (Ernesto Guevara, citado por Turner; 2010: 102-104).

Acerca de la educación del pueblo en los procesos de transformación, de la relación entre estructura y subjetividad encontramos estas palabras que son relevantes para pensar la pedagogía:

"Si nosotros logramos desentrañar, bajo la maraña de los papeles, las intrincadas relaciones entre los organismos y entre secciones de organismos, la duplicación de funciones y los frecuentes "baches" en que caen nuestras instituciones, encontramos las raices del problema y elaboramos normas de organización, primero elementales, más completas luego, damos la batalla frontal a los displicentes, a los confusos y a los vagos, reeducamos y educamos a esta masa, la incorporamos a la Revolución... al mismo tiempo, continuamos sin desmayar, cualesquiera que sean los inconvenientes confrontados, una gran tarea de educación a todos los niveles, estaremos, en condiciones de liquidar en poco tiempo el burocratismo" (Ernesto Guevara, citado por Turner; 2010: 107).

En 1962 se realiza en Montevideo la Conferencia denominada "Alianza para el Progreso" convocada por Estados Unidos para frenar el avance de las ideas de la revolución cubana en toda América, y en la que los postulados desarrollistas se plantearon como alternativa para paliar la situación de pobreza que viven los pueblos de América. En esta conferencia que pretendía ser "técnica" Guevara intervino planteando que Cuba interpretaba que ésta era una conferencia política, ya que es imposible separar la economía de la política, que "no puede haber técnicos, que hablen de técnicas, cuando está de por medio el destino de los pueblos" (Guevara; 2006:13) en donde Guevara expone en su calidad de Ministro de Industrias ante Ministros de Economía de América los principios y logros de la Revolución Cubana. Planteó en esa oportunidad que, en el terreno educacional, Cuba prácticamente ya había conseguido todo lo que se proponía la Conferencia como una meta para diez años.

"Hay un punto en que me gustaría detenerme un minuto; es en la educación. Nos hemos reído del grupo de técnicos que ponía a la educación y a la sanidad como condición sine qua non para iniciar el camino del desarrollo. Para nosotros eso es una aberración, pero no es menos cierto que una vez. iniciado el camino del desarrollo, la educación debe marchar paralela a él. Sin una educación tecnológica adecuada, el desarrollo se frena. Por lo tanto, Cuba ha realizado la reforma integral de la educación, ha ampliado y mejorado servicios educativos y ha planificado integralmente la educación. Actualmente está en primer lugar en América Latina en la asignación de recursos; se dedica el 5,3\% del ingreso nacional. Los países desarrollados emplean del 3 al 4, y América Latina del uno al 2\% del ingreso nacional. En Cuba el 28,3\% de los gastos corrientes del Estado son para el Ministerio de Educación; incluyendo otros organismos que gastan en educación, sube ese porcentaje al 30\%. Entre los países latinoamericanos, la mayoría emplean el 21\% de su presupuesto... Es el primer pais de Latinoamérica que satisface plenamente las necesidades de instrucción primaria para toda la población escolar, aspiración del proyecto principal de la UNESCO en América Latina para 1978, ya satisfecha en Cuba." (Guevara; 2006:42).

Y enumera a los delegados de la conferencia las medidas que hicieron posible esas cifras en principio, la nacionalización de la enseñanza, haciéndola laica y gratuita y permitiendo el aprovechamiento total de sus servicios, y otra serie de medidas y dineros destinados a la 


\section{Pedagogias emancipatorias en el Abya Yala: Legados y reflexiones urgentes}

educación, a impresión de libros, a construcción de escuelas, formación docente y materiales didácticos.

"Este año, en Cuba, como anuncié, se liquida el analfabetismo. Es un maravilloso espectáculo. Hasta el momento actual 104.500 brigadistas, casi todos estudiantes entre 10 y 18 años, han inundado el país de un extremo a otro para ir directamente al bohio del campesino, para ir a la casa del obrero, para convencer al hombre anciano que ya no quiere estudiar, y liquidar, así, el analfabetismo en Cuba. Cada vez que una fábrica liquida el analfabetismo entre sus obreros, iza una bandera azul que anuncia el hecho al pueblo de Cuba; cada vez que una cooperativa liquida el analfabetismo entre sus campesinos, levanta la misma enseña. Y 104.500 jóvenes estudiantes, que tienen como enseña un libro y un farol, para dar la luz de la enseñanza en las regiones atrasadas, y que pertenecen a las Brigadas "Conrado Benitez.", con lo cual se honra en nombre del primer mártir de la educación de la Revolución Cubana, que fue aborcado por un grupo de contrarrevolucionarios por el grave delito de estar en las montañas de nuestra tierra, enseñando a leer a los campesinos" (Guevara; 2006: 43-44).

Regina Algramonte Rosell señala en esta línea que,

“Cuando se revisan las estadísticas salta a la vista el alto nivel de participación popular: 120632 alfabetizadores populares, 100000 estudiantes brigadistas "Conrado Benitez”, 13016 brigadistas obreros "Patria o Muerte", 34772 mil maestros y profesores como técnicos, 227600 personas en total. Fueron alfabetizadas 707212 personas, con lo que se redujo la tasa de analfabetismo del 23,6\% al 3,9\%. Ese año, 1961, la UNESCO declaró a Cuba "Territorio Libre de Analfabetismo" (Algramonte Rosell; 2014: 38).

\section{Brasil ... acerca de Paulo Freire y la pedagogía en los prolegómenos del genocidio y las dictaduras en el continente. Una corriente de pensamiento y acción gestada en las trincheras}

Brasil es la cuna de uno de los referentes de la Educación Popular, Paulo Freire, y también de una de las primeras dictaduras del continente en las décadas de los '60 y '70. Recuperar y tensionar la experiencia social con la obra de un referente como Paulo Freire permite aproximarse a la historia social del continente, tal como lo señala una pequeña biografía elaborada en el Instituto que lleva su nombre.

"Paulo Reglus Neves Freire nasceu no dia 19 de setembro de 1921, no Recife, Pernambuco, uma das regiões mais pobres do país, onde logo cedo pôde experimentar as dificuldades de sobrevivência das classes populares. Trabalhou inicialmente no SESI (Serviço Social da Indústria) e no Serviço de Extensão Cultural da Universidade do Recife"

En el nordeste brasilero, la región del desierto brasilero, zonas de sequías y de enorme pobreza, en Pernambuco nacía en la década del '20, para más adelante en el contexto de sustitución de importaciones y con la expansión de la industria trabajó en el Servicio Social de la Industria en el sector de educación. Fue años más tarde que impulsa en Angicos primero y luego en todo Brasil un trabajo ligado a los campesinos y campesinas analfabetos/as. A grandes rasgos pretendemos recuperar y seguir contribuyendo derribar mitos en torno a la praxis de Paulo Freire, para ello partimos de la relación entre la experiencia social y la teorización sobre la misma que fue haciendo a lo largo de su vida, en diferentes períodos, signados todos ellos por procesos políticos que se vivían en los países donde él desarrolló su praxis. Esto le dio un dinamismo e historicidad al pensamiento que es preciso recuperar. 
Celso de Rui Beisiegel(2002) asegura que las ideas de Paulo Freire comenzaron a ser conocidas en Brasil a partir de 1963, cuando se empezó a conocer más acerca de su método de alfabetización para adultos. La propuesta de esa educación conscientizadora fue desarrollada y practicada en Brasil desde 1961, en una realidad social, política e ideológica en transformación, se vivía un momento complejo en la Guerra Fría, la revolución cubana se había definido por el bloque socialista, el nordeste brasileño era visto en Brasil y afuera, como una probable segunda Cuba. La disputa por el poder al interior de Brasil, reflejaba las tensiones vividas en el mundo. A ello se sumó la renuncia del presidente Janio Quadros y la difícil conducción del vice presidente João Goulart a la presidencia radicalizaron la lucha política interna. Según Besisiegel (2002), todo contribuía para hacer de la alfabetización por el método de Paulo Freire uno de los factores de esa radicalización política.

Desde los primeros ensayos de teorización de Paulo Freire, en 1959 hasta abril de 1964, en que sus actividades fueron prohibidas por el golpe militar, desarrolló un trabajo intenso en el campo de la educación de adultos. Al final de ese ciclo, sus ideas y, particularmente, su método de alfabetización ya ejercía gran atracción entre los jóvenes, en especial en la juventud católica, y eran adoptados por gran parte de los movimientos que de alguna forma se encontraban involucrados en la práctica de la educación popular en Brasil (Beisiegel; 2002). En la propuesta de alfabetización, los procedimientos eran aparentemente sencillos y las ideas que sostenían los materiales estaban dotadas de la fuerza de su contenido ideológico, por lo que era bien recibido por jóvenes universitarios. La "concientización", la autopromoción de las poblaciones desfavorecidas, el estímulo a la participación, la construcción de la democracia y la promoción del desarrollo, se materializaban coherentemente en la propuesta de la educación "concientizadora". Freire consiguió traducir en esta propuesta de educación, gran parte de la creatividad y de las expectativas de los movimientos sociales de la época. (Beisiegel; 2002).

La educación, para Paulo Freire, nunca fue entendida como políticamente neutral, pues desde sus primeros trabajos había optado, de manera clara, por la defensa de los intereses de la población más humilde y las características de la propuesta de alfabetización estrechaban esta relación entre política y educación explicitando los contenidos políticos inherentes al proceso educativo. La discusión de las condiciones de vida de los adultos analfabetos, en realidad correspondía a la discusión de las circunstancias de vida de los sectores más desfavorecidos de la población.

La propuesta fue tomada principalmente por jóvenes universitarios de la "izquierda católica" pero, también, por diversas corrientes de las "izquierdas"; la discusión sobre las condiciones de vida de las poblaciones subalternas, en el contexto político-ideológico fue tomado a partir de su potencial para un proceso de formación de la conciencia de clase. Nos señala Celso de RuiBeisiegelque entre los objetivos de sus investigaciones en esos años Paulo Freire ya no mencionaría entre ellos la construcción de una sociedad capitalista floreciente en el país, ya no confiaba en el capitalismo como sistema económico y se incluía entre los católicos progresistas. Señala además que Educación como Práctica para la Libertad fue resultado de un trabajo desarrollado para difusión más amplia de los análisis gestados en experiencias previas en Brasil, si bien el libro fue concluido en Santiago de Chile, en 1965, cerca de un año después de la salida al exilio. 
44 Pedagogias emancipatorias en el Abya Yala: Legados y reflexiones urgentes

\section{Según la biografía del Instituto Paulo Freire:}

"A metodologia por ele desenvolvida foi muito utilizada no Brasil em campanhas de alfabetização e, por isso, ele foi acusado de subverter a ordem instituida, sendo preso após o Golpe Militar de 1964. Depois de 72 dias de reclusão, foi convencido a deixar o país. Exilou-se primeiro no Chile, onde, encontrando um clima social e politico favorável ao desenvolvimento de suas teses, desenvolveu, durante 5 anos, trabalhos em programas de educação de adultos no Instituto Chileno para a Reforma Agrária (ICIRA). Foi ai que escreven a sua principal obra: Pedagogia do oprimido" (Instituto Paulo Freire; 2002).

Como señalábamos, "Educación como práctica de la libertad" (Freire; 1982) fue sistematizado en Chile. Varios capítulos desarrollan ideas ya planteadas en escritos entre el 59 y el $63^{6}$. El propio Paulo Freire en entrevistas realizadas en Chile, en 1972 y más tarde en entrevistas en los 80 (Torres; 1985), califica de ingenuas algunas de las posiciones de sus primeros trabajos en los 50' y 60', sostenía que las críticas que se le han hecho eran hechas principalmente a partir de aquellos primeros trabajos, que indiscutiblemente, abrigaban posiciones débiles e ingenuidades (Beisiegel; 2002). Aunque reconocía que la práctica que desarrollaba contemplaba las determinaciones estructurales de una sociedad dividida en clases, aunque los escritos y reflexiones no dieran cuenta de esto (luchas políticas, disputas ideológicas, grupos sociales).

En realidad Freire convivió, desde su exilió en Chile en 1964, con intelectuales y militantes políticos situados más a su "izquierda" (Beisiegel;;2002), defensores de concepciones del hombre y de la dinámica social alejadas de su praxis en Brasil. Incluso las entrevistas que concedió fueron entrevistas que lo invitaron a polemizar con su propio pensamiento y a reflexionar, debatir, estudiar, dialogar. Es reconocido que las transformaciones más acentuadas de perspectivas pueden ser captadas en el transcurso de sus escritos, desde el libro Pedagogía del Oprimido, de 1970. Si bien sostuvo los temas centrales en sus reflexiones, tales como las características de la conciencia, la crítica a la educación "domesticadora", la discusión acerca de la naturaleza del hombre y del proceso de su humanización, los ejes de una pedagogía libertadora, el papel central del diálogo en la educación, la participación, etc., en una segunda etapa estos mismos temas los analizó desde ese humus sociológico de aqueldiálogo con numerosos intelectuales considerados "de izquierda", también comprometidos con los sucesos de la época. ${ }^{7}$

En 1969, Paulo Freire había dejado Chile para desempeñar la función de associate professor en la Universidad de Harvard. Luego se exilia en Ginebra, donde, a partir de 1979, ocupó la posición de consultor especial del Departamento de Educación del Consejo Mundial de las Iglesias. Desde allí viaja a apoyar las campañas de alfabetización en los países africanos que estaban liberándose (Angola, Santo Tomé, Príncipe, Guinea Bissau). Los trabajos de Paulo Freire fueron desarrollados desde programas, políticas o experiencias que tenían una aspiración de universalizar las propuestas, tal vez en experiencias más sencillas en primeras 
instancias, pero siempre con miras hacia la transformación social y en el contexto de procesos revolucionarios o de reformas profundas en las sociedades. Su primera experiencia en Angicos y finalmente en todo Brasil fueron los recorridos de su "método" hasta que en 1964 fue abortada la experiencia por el golpe de estado. Igualmente, en Chile, experiencias con campesinos inicialmente y desde el ICIRA mas tarde. Aportó en el contexto de países liberándose del colonialismo, como Guinea Bissau, Santo Tomé, Príncipe o en un contexto revolucionario como Nicaragua.

Se rescatan tres cuestiones no menores en la praxis de Freire, que son el resultado de un pensamiento dinámico, histórico. Una es su autocrítica respecto de la cuestión de género, de no haber considerado a lo largo de sus escritos la opresión histórica de las mujeres incluso desde una autocrítica en su lenguaje, se pueden hallar estas reflexiones de Freire, así como miradas al respecto en los trabajos de Claudia Korol, quién ha reinventado esta corriente desde su potencialidad para la praxis político-pedagógica feminista $(2007 ; 2016 ; 2017)$. El otro tema es su referencia, en los últimos años, a la necesidad de avanzar en concepciones no antropocéntricas sino más bien que tengan en consideración la tierra, la naturaleza, y plantea la necesidad de pensar desde una Pedagogía ligada a la tierra, de hecho, acompañó el nacimiento del Movimiento de Trabajadores Rurales Sin Tierra. Este punto nada menor en los tiempos donde la naturaleza se halla interpelada, siendo devastada por emprendimientos económicos de carácter extractivista que ponen en peligro ni más ni menos que la supervivencia del planeta; estos tiempos que se viven señalan la necesidad de realizar lecturas críticas de esa oposición entre hombre y naturaleza, el hombre que pone a la naturaleza a su servicio, presente en los primeros escritos de Freire, y puntualmente en "Educación como Práctica de la Libertad" (1982). Lecturas que tengan en consideración concepciones si presentes entre los pueblos originarios.

Finalmente rescatar en su regreso a Brasil del exilio en 1980, el compromiso militante por la construcción política y su participación en la fundación del Partido de los Trabajadores. Un artículo que es poco conocido de Freire, del que realizamos una traducción, se llama "El partido como educador - educando" (Freire; 1981), publicado en una compilación de trabajos de intelectuales que adhirieron a la fundación del Partido de los Trabajadores de Brasil, da cuenta de esta preocupación militante de Paulo Freire. La preocupación por pensar en la intervención política y asumirse el mismo más bien como un actor político que como pedagogo, ha estado presente en la trayectoria de vida, en la obra, esto es en la praxis de Freire. Nuñez Huratdo relata en el prólogo a "Pedagogía de la Esperanza", un episodio vivido en 1977 en San José de Costa Rica,

“... una noche -la última- tuvimos una pequeña fiesta de celebración y despedida. Éramos apenas unos cuantos. Inevitablemente, poco a poco, sin perder el gusto y el ánimo de celebración festiva, la conversación volvió a ser la protagonista de la fiesta y las ideas, el alimento de la misma. Hablábamos del tema de la seguridad personal, de las amenazas siempre presentes por parte de los enemigos de toda causa justa en cualquier lugar del mundo. En la reunión habia varios que explícitamente se entendían y actuaban desde una óptica y compromiso religioso. Aunque quizá todos -o la gran mayoría éramos cristianos, habia como dos tendencias no contradictorias pero sí con diferentes matices: quienes se empeñaban en entender la Pedagogía del oprimido desde una perspectiva más propiamente pedagógica (que dio origen a aquella tendencia psicosocial del pensamiento freireano que obligó al propio Paulo a auto criticarse por 10 que, aun sin pretenderlo, habia provocado con algunas de sus afirmaciones ligadas al tema de la concientización) y los que la entendiamos también en su dimensión política. 
46 Pedagogias emancipatorias en el Abya Yala: Legados y reflexiones urgentes

La conversación fue riquísima y de gran impacto para todos. Cuando terminó la fiesta, una amiga nos llevó en su carro al hotel. En el camino, me resultó imposible no hacer algún comentario al respecto, como queriendo todavia aprovechar aquellos minutos para saborear el "postre" de aquella rica sesión. "Es muy claro -me dijo más o menos- que los compañeros mantienen todavía una posición muy ingenua que, siendo bonesta y comprometida, manifiesta su posición religiosa de influencia metafísica. Y por eso tratan de interpretarme a mí como pedagogo; mas yo te digo a ti que soy sustantivamente político y sólo adjetivamente pedagogo." Estas últimas palabras si fueron exactamente dichas así, porque nunca se me pudieron olvidar. Me marcaron para toda la vida, y cuando las lei en otros trabajos, siempre evoqué esta noche inolvidable en la que Paulo se definió [...]" (Nuñez Hurtado; 2011: 14).

Desde su militancia en el Partido de los Trabajadores, Paulo fue designado como Secretario de Educación de San Pablo en 1989, sin embargo no terminó de cumplir su mandato en este cargo ya que en 1991 renuncia anticipadamente retornando a dictar clases en la Universidad Católica de San Pablo. Su último viaje a la Argentina lo realizó poco antes de morir, invitado por Roberto Tato Iglesias, educador popular, docente de la Universidad de San Luis y uno de los fundadores del Movimiento de Educación Popular de la Universidad Trashumante. Falleció ese mismo año, en 1997 en San Pablo.

\section{Pedagogías y contexto actual: miradas urgentes en diálogos}

En el contexto de crisis civilizatoria en que atravesamos como humanidad y actualmente de colapso civilizatorio, la lucha de los pueblos por su autodeterminación, la de sus territorios y de los cuerpos han tenido y contado con miradas ancladas en la corriente educación popular. Se entiende que actualmente la Corriente Educación Popular es una corriente con una enorme vitalidad en América Latina, el Abya Yala o Nuestramérica. Experiencias diversas y reflexiones transitan a la par. Esta corriente ética, política, epistemológica, metodológica que es la que ocupa dialogo en la actualidad con organizaciones sociales urbanas, campesinas, indígenas, feministas y de derechos humanos en el continente. En este nutrirse mutuamente entre la corriente de pensamiento y acción que es la Educación Popular tal como la denominara Carlos Nuñez Hurtado (2005) y las organizaciones y movimientos está gestándose y puede gestar otros modos de hacer política. Las perspectivas que abren las miradas en torno a la interculturalidad y puntualmente la interculturalidad latinoamericana (Perez Ruiz; 2009; Walsh; 2016) es una puerta ineludible para el pensar y hacer educación desde el continente.

Las corrientes de los feminismos y la denuncia acerca de los femicidios, feminicidios en el continente y las múltiples estrategias para visibilizar, denunciar apelan a las prácticas de la educación popular, el arte en las calles de los países latinoamericanos en la denuncia de estos crímenes es una herramienta y un lenguaje que solo como muestra se pueden citar "Un violador en tu camino", la perfomance chilena pero que a lo largo de los países se encuentra replicada con manifestaciones de este tipo. Los talleres de las compañeras de Pañuelos en Rebeldía en Argentina, colectivo cuya praxis se inscribe en esta corriente pedagógica latinoamericana es una experiencia sumamente relevante de este aunar feminismo y educación popular.

En esta America Latina donde se asiste a una pedagogía de la crueldad, como la refiriera Rita Segato (2018) a esa política y pedagogía que se ha gestado en el continente el arma política frente a tanta injusticia es la autodeterminación de los pueblos. Lo es para la defensa de los cuerpos y lo es para la defensa de los territorios como bien invitan las feministas comunitarias 
indígenas a pensarlo (Gargallo; 2014). Esta concepción de territorio en un contexto de avance del extractivismo, con referentas asesinadas como Berta Caceres pero que son miles y miles que resultan víctimas de asesinatos, desapariciones o encarcelamientos en nuestro continente. Las luchas hoy son por la vida, por el medio ambiente, por las defensas territoriales y en estas luchas las estrategias de educación popular son una herramienta valiosísima de "construcción masiva" como solía llamar Carlos Falaschi, educador popular y activista argentino, también muy cercano en su exilio en Suiza a Paulo Freire y en Argentina de andares junto a los movimientos socio ambientales, indígenas y educacionales.

Los movimientos campesinos, una referencia es el Movimiento Sin Tierra de Brasil, han apelado a la corriente de Educación Popular. Esta praxis educativa se ha extendido en el continente en estos movimientos socio territoriales en especial. Asimismo, estos movimientos y espacios más pequeños que luchan por la soberanía alimentaria, por la agroecología o contra los agrotóxicos también han sido influidos por las miradas de la educación popular en su praxis. Las organizaciones de derechos humanos y de los pueblos, en su denuncia de la deuda externa de los países, deuda fraudulenta también suelen emplear y atravesar sus espacios formativos por miradas pedagógicas ancladas en esta corriente. Finalmente, la praxis en derechos humanos con infancias y juventudes, anclan en estas miradas respecto de la educación, de lxs sujetxs, del saber popular.

\section{Conclusiones}

Este recorrido por dos referencias ineludibles de la historia de la corriente educación popular como lo son la revolución cubana y la experiencia brasilera permiten aproximarse a algunas reflexiones acerca de la dimensión política de la tradición pedagógica. Asimismo, se reflexiona acerca de las experiencias contemporáneas en las que abrevan planteamientos de esta corriente. Ahondar en la historia de esta tradición pedagógica puede ayudar mucho a pensar y hacer una educación en el continente anclada en los contextos específicos y con una proyección emancipatoria. Las reflexiones en torno a la interculturalidad, feminismos, luchas socioambientales, en derechos humanos y de los pueblos y, en definitiva, de la autodeterminación de los pueblos están enriqueciendo y debieran nutrir a esta corriente.

Asimismo, ahondar en los procesos gestados en el continente y profundizar en la influencia de los pedagogos anarquistas en la corriente de Educación Popular sería sumamente valioso, la influencia de Illich por ejemplo. Así mismo la de pedagogos anarquistas españoles en la praxis en las organizaciones de inmigrantes que gestaron sus organizaciones y espacios educativos resultaría muy valioso. El peso del anarquismo y de la pedagogía anarquista en Brasil, por ejemplo y la influencia que dichos pensamientos y acciones han tenido influencia en los movimientos educacionales.

\section{Referencias}

ALGRAMONTE ROSELL, R., 2014, "Diálogos con la cuba revolucionaria: alfabetizar desde y para la libertad", publicado en Revista Nuestramerica, Número Especial "Sugerencias para la Alfabetización. Programa de educación de los Trabajadores". Pp. 31-38. Disponible en https://revistanuestramerica.cl/ojs/index.php/nuestramerica/article/view/106

BARQUERA, H. 1985. Las principales propuestas pedagógicas en América Latina. En: Lecturas sobre educación de adultos en América Latina. Compiladores: Pablo Latapi y Alfonso Castillo. CREFAL/OEA. Pátzcuaro, Michoacán. México. 


\section{Pedagogias emancipatorias en el Abya Yala: Legados y reflexiones urgentes}

FREIRE, P., 1981, “O partido como educador-educando", en Alberto Damasceno y otros (Trad. Jessica Visotsky), A educação como um ato político partidario, San Pablo, Cortez Editora.

FREIRE, P., 1982, Educación como práctica de la libertad, Buenos Aires, Siglo XXI.

GADOTTI, M., 2013, “Ahora en las manos y en los corazones de las nuevas generaciones”, Prólogo a Inventamos o Erramos. Educación Popular y lucha de clases, Neuquén, Educo.

GARGALLO, F., 2014, Feminismos desde AbyaYala. Ideas y proposiciones de las mujeres de 607 pueblos en nuestra américa, Ciudad de México, Editorial Corte y Confección. Disponible en: https:// francescagargallo.files.wordpress.com/2014/01/francesca-gargallo-feminismos-desde-abyayala-ene20141.pdf

GILMAN, C., 2003, Entre la pluma y el fusil. Debates y dilemas del escritor revolucionario en América Latina, Buenos Aires, Siglo

XXI.

GUEVARA, Ernesto “Che”, 2006, (Reed.) Punta del Este. Proyecto Alternativo de desarrollo para América Latina, La Habana, Edit. OceanSur.

INSTITUTO PAULO FREIRE, 2002, Paulo Freire: Pequena Biografia, San Pablo, Mimeo.

KOROL, C., 2007, Hacia una pedagogia feminista: géneros y educación popular, Buenos Aires, Ed. El Colectivo- América Libre.

KOROL, C., 2016, Feminismos populares: pedagogías y políticas, Buenos Aires, Chirimbote-America Libre. KOROL, C., 2017, Dialogo de saberes y pedagogía feminista, Buenos Aires, América Libre.

MONTERO, H., 2011, “Apuntes de un sueño armado, Primera Parte”, En Revista Sudestada, Edición extra, Agosto 2011.

NUÑEZ HURTADO, C., 2005, Educación Popular. Una mirada de conjunto. En Revista Decisio No 10. CREFAL. México. Enero-abril 2005.

NUÑEZ HURTADO, C., 2011, "Prólogo", en Paulo Freire, Pedogogía de la Esperanza: un reencuentro con la pedagogía del oprimido, México, Siglo XXI.

PEREZ RUIZ, M., 2009, "¿De qué hablamos cuando nos referimos a lo intercultural? Reflexiones sobre su origen, contenidos, aportaciones y limitaciones" en Laura Valladares de la Cruz y otras (Coord.), Estados plurales: el reto de la diversidad, Dto. de Antropología UAM Iztapalapa, Mexico.

PINEDO, J., 2010, . "El concepto Segunda Independencia en la historia de las ideas en América Latina: Una Mirada desde el Bicentenario". Publicado en Revista Atenea (Concepción), (502), 151-177. Disponible en: https://dx.doi.org/10.4067/S0718-04622010000200009

RODRIGUEZ BRANDAO C. 1993. Caminos cruzados: formas de pensar y hacer educación en América Latina. En: Gadotti, M. y Torres, C.A. Educación Popular. Crisis y perspectivas. Miño y Dávila. Bs. As..

ROIG, A., 2003, "Necesidad de una segunda independencia", publicado en Revista Latinoamericana Polis, Num.4, Disponible en: https://journals.openedition.org/polis/7137

RUI BEISIEGEL, CELSO, 2002, “Observaciones sobre la Teoría y la Práctica en Paulo Freire", en Mirandum- Estudos e Seminarios -ANO III N. 7 Jan-Jun 99 - Disponible en: http://www.hottopos.com/mirand7/observaciones_sobre_la_teoria_y_htm. Fecha de consulta 8-8-20

SEGATO, R., 2018, Contra-pedagogías de la crueldad, Buenos Aires, Ed. Prometeo.

TORRES, R. M., 1985, “Sobre educación popular: entrevista a Paulo Freire”, En Revista Interamericana de Educación de Adultos 8 (1-2) , pp. 117-153.

TURNER MARTI, L., 2010, El pensamiento pedagógico del ‘Che”, Buenos Aires, Nuestra América, Buenos Aires.

VISOTSKY, J., 2012, " Educación Popular en América Latina: legados y desafíos en el contexto de crisis mundial", en Revista Atenas, N¹8, Universidad de Ciencias Pedagógicas, "Juan MarinelloVidaurreta". Matanzas, Cuba. 2012. Dispoible en: http://atenas.mes.edu.cu/index.php/atenas/issue/view/5.

WALSH, C., 2007, "¿Son posibles unas ciencias sociales/culturales otras? Reflexiones en torno a las epistemologías decoloniales”, Publicado en Revista NómadasNum. 26., pp.102-113. Colombia.

WALSH, C., 2016, "Interculturalidad y Educación Intercultural", disponible en http://catherinewalsh.blogspot.com.ar/2010/12/interculturalidad-critica-y-educacion.html. Fecha de consulta 10-6-16

Padilla, A. (2011, diciembre). Inclusive Education of Persons with Disabilities. Rev Colomb Psiquiatr. 40(4 ).

Silver, H. (1995). Reconceptualizing Social Disadvantage: Three Paradigms of Social Exclusion. Ginebra: Instituto Internacional de Estudios Laborales, Programa de Desarrollo de las Naciones Unidas. 
Redacción Educación. (13 de marzo de 2020). Los colegios públicos de Colombia no están preparados para dar clases virtuales. El Espectador https://www.elespectador.com/coronavirus/los-colegios-publicosde-colombia-no-estan-preparados-para-dar-clases-virtuales-articulo-909149/

Tilly, C. (1999). Durable Inequality. Berkeley, CA: University of California Press.

UNESCO (2005). Informe de seguimiento de la educación para todos. UNESCO.

UNESCO-UIS (2015). Browse by theme: Education. Data Centre, UNESCO Institute for Statistics. www.uis.unesco.org/DataCentre/Pages/BrowseEducation.aspx

UNICEF (2012), Estudio de Pais: Colombia, Iniciativa Global por las Niñas y los Niños fuera de la Escuela, Fondo de las Naciones Unidas para la Infancia.

White, D. y Le Cornu, A. (2011, 5 de septiembre). Visitantes y Residentes: Una nueva tipología para la participación en línea. First 